\title{
Outbreak of norovirus infection in a hotel in Oslo, Norway, January 2011
}

B Guzman-Herrador (BernardoRafael.Guzman.Herrador@fhi.no)1,2, B T Heier ${ }^{1}$, E J Osborg ${ }^{3}$, V H Nguyen ${ }^{3}$, L Vold

1. Norwegian Institute of Public Health, Oslo, Norway

2. European Programme for Intervention Epidemiology Training (EPIET), European Centre for Disease Prevention and Control (ECDC), Stockholm, Sweden

3. Norwegian Food Safety Authority, Oslo, Norway

Citation style for this article:

Guzman-Herrador B, Heier BT, Osborg EJ, Nguyen VH, Vold L. Outbreak of norovirus infection in a hotel in Oslo, Norway, January 2011.

Euro Surveill. 2011;16(30):pii=19928. Available online: http://www.eurosurveillance.org/ViewArticle.aspx?Articleld=19928

Article published on 28 July 2011

A total of 56 people were affected with gastroenteritis after attending a one-day meeting in a high-quality hotel in the centre of Oslo, Norway, at the end of January 2011. A complete outbreak investigation was carried out. The microbiological investigation confirmed that the outbreak was caused by norovirus. All participants at the meeting were invited by email to complete an online questionnaire asking for information on demographic data, symptoms and food consumption. The results of the epidemiological investigation of the food items served were inconclusive and the source and transmission route of this outbreak remains unclear. However, the environmental investigation highlighted several irregularities in the kitchen that may have enabled the spread of the virus. Specific cleaning procedures and rules were set up for the kitchen staff. As a consequence of this outbreak investigation, the hotel is planning to change its internal routine protocols, for example, samples of food items served at every meal during an event will be stored.

\section{Introduction}

Noroviruses are a group of RNA viruses belonging to the Caliciviridae family that cause gastroenteritis in humans. They are highly contagious and as few as 10 viral particles may be sufficient to infect an individual [1]. During outbreaks of gastroenteritis due to norovirus infection, several modes of transmission have been documented, the most frequent being food-borne, followed by subsequent secondary person-to-person transmission [1]. Norovirus is known to be responsible for most gastroenteritis outbreaks in winter in industrialised countries [2], such as in the European Union. In Norway, it is the most frequently reported suspected cause of food-borne outbreaks [3].

On 31 January 2011, the Norwegian Institute of Public Health (NIPH) was informed about a possible outbreak of gastroenteritis among people attending a one-day meeting organised by an international company. The meeting was held on 28 January, in a hotel in the centre of Oslo: it included around 900 participants from all over Norway. According to the initial information received, at least 30 participants had fallen ill with vomiting and diarrhoea after attending the meeting, but none required hospitalisation. The Department of Infectious Disease Epidemiology of the NIPH, in collaboration with the Food Safety Authority and the Municipal medical officer of Oslo, decided to carry out an outbreak investigation in order to measure the extent of the outbreak, identify the source, pathogen and the vehicle of transmission, and implement control measures to prevent further outbreaks. The investigation was started on 31 January.

\section{Methods}

A retrospective cohort study was conducted among all the persons who attended the meeting.

We defined an outbreak case as a person who attended the one-day meeting at the hotel in Oslo on 28 January 2011 and developed diarrhoea and/or vomiting within the following three days. The Food Safety Authority gathered information on food and drink served during the meeting. There were four servings (breakfast, lunch, snack and dinner); some of the dishes were prepared in the kitchen of the hotel, while others were cooked in other places and delivered to the hotel, ready to be served.

The NIPH Outbreak Team adapted a standard foodborne disease Internet-based questionnaire for the current outbreak, to be completed by the attendees. The questionnaire was partly based on the information from the Food Safety Authority on what was served, and contained questions on demographic data in addition to symptoms and food consumption during the meeting. On 4 February, a link to the questionnaire was sent to all the attendants of the meeting via email by the human resources department of the company who organised the meeting. One week later, on 10 February, a reminder was sent to those who had not answered yet, to try to increase the response rate. On 21 February, the online questionnaire was closed. Once the data from the participants were collected, we carried out a descriptive and univariate analysis. 
On 31 January, the NIPH contacted the human resources department of the company and asked them to encourage all people who reported being sick after attending the meeting to go to a medical facility to submit a stool sample.

The Food Safety Authority went to the hotel on 2 February to carry out a routine environmental inspection of the kitchen.

\section{Results}

\section{Epidemiological investigation}

A total of 880 people from all over Norway attended the one-day meeting on 28 January in the hotel. The questionnaire was sent to all of them and 391 replied (response rate: 44\%): 358 answered the questionnaire within the first week, while 33 replied after the reminder. Of the respondents, 206 (53\%) were female and $64 \%(n=250)$ were between 40 and 59 years old (range: 20-74 years). They included people working in various offices around the country. Regarding symptoms, 90 respondents (23\%) reported to have had at least one of the symptoms listed in the questionnaire (vomiting, diarrhoea, nausea, abdominal pain and fever), but only 56 matched the case definition (attack rate: $14 \%$ ). One person reported to have had diarrhoea during the night before the meeting and thus did not meet the case definition. Of the 56 cases, 30 reported having had only diarrhoea, seven only vomiting and 19 both symptoms. As seen in Table 1 , several cases reported having had more symptoms than those included in the case definition.

\section{TABLE 1}

Clinical features of outbreak cases due to norovirus infection, one-day meeting, Oslo, Norway, 28 January $2011(n=56)$

\begin{tabular}{|c|c|}
\hline Clinical feature & Number \\
\hline Type of symptom ${ }^{\text {a }}$ & 30 \\
\hline Only diarrhoea & 7 \\
\hline Only vomiting & 19 \\
\hline Both diarrhoea and vomiting & 30 \\
\hline Nausea & 26 \\
\hline Abdominal pain & 21 \\
\hline Fever & \\
\hline Duration of symptoms & 6 \\
\hline Less than one day & 31 \\
\hline 1-2 days & 19 \\
\hline More than 2 days & 0 \\
\hline Deaths & $\mathbf{0}$ \\
\hline Hospitalisation & 4 \\
\hline Went to the doctor & \\
\hline
\end{tabular}

a Symptoms were not further defined in the questionnaire.
The date and time of onset of symptoms for the 56 cases are shown in the Figure. The first case became ill the same evening as the meeting. Most cases became ill 48 hours after the meeting, on 30 January, with most falling ill between noon and midnight. The last cases reported symptom onset 72 hours after the meeting.

There was no difference in the risk of infection between female and male cases. The cases worked in several different offices around Norway and there was no cluster of cases from any particular office or city. Those aged 60 years and older $(n=11)$ had a higher attack rate $(34 \%)$ and were almost three times more likely to have been sick than younger people. Very few cases reported having had contact with one or more persons who were sick during the meeting or in the four days before the meeting (Table 2). Only six cases reported having eaten something outside of the hotel during the meeting. We did not gather information on whether participants had stayed in the hotel the night before or the night after the meeting.

People exposed to seven food items served during the meeting had a higher risk of developing symptoms (Table 3). Items eaten by most of the cases were those eaten during the dinner. However, the results were not statistically significant since most of the attendants were exposed to the same foods. The two food items leading to the highest attack rate among those

\section{FIGURE}

Outbreak cases due to norovirus infection, one-day meeting, Oslo, Norway, 28 January $2011(n=56)$

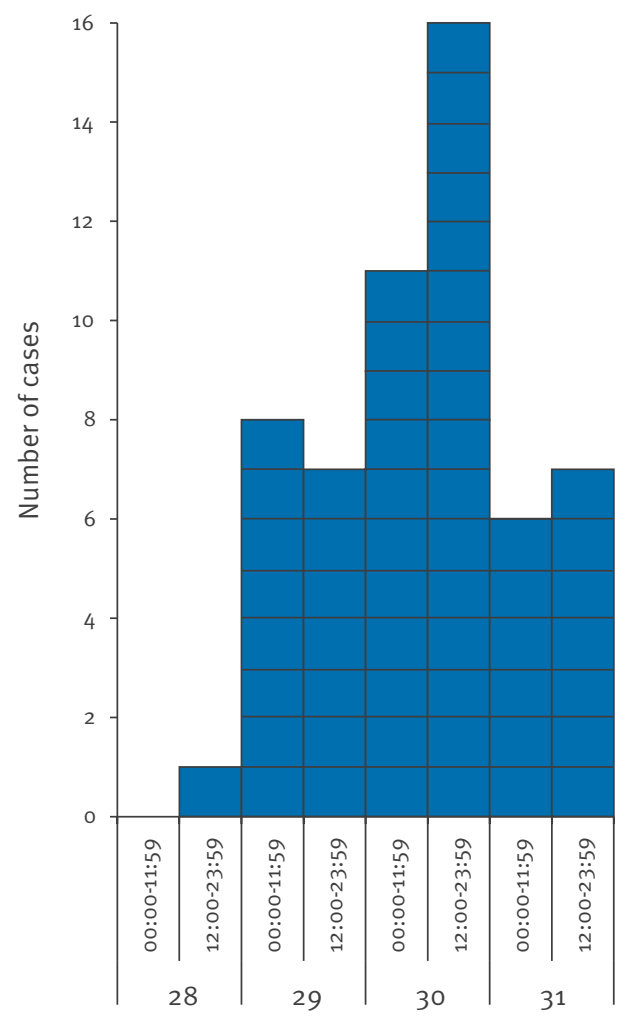

Date and time of symptom onset (January 2011) 
exposed and the lowest $\mathrm{p}$ value were wraps and sandwiches. However, they only accounted for $52 \%$ and $70 \%$ of the cases, respectively (Table 3 ).

In a second univariate analysis we excluded cases who reported having had contact with people who were sick before or during the meeting. This was done in order to separate cases who were symptomatic or incubating the disease before the meeting from those who became ill as a result of the meeting. The results of this second analysis were similar to those previously calculated in the first analysis.

We also considered whether attending only one specific serving represented a higher risk of becoming a case. Results of a stratified analysis by meal were inconclusive since almost all the cases had more than one meal.

\section{Microbiological investigation}

Stool samples were taken from three of the four cases who visited a doctor: all were positive for norovirus. No further genotyping was carried out. The samples were also analysed for Campylobacter spp. Salmonella spp., Yersinia spp. and Shigella spp. - such tests are routinely performed on faecal samples in Norway. No further tests were carried out. No samples were taken from the food handlers or other kitchen employees.

It was not feasible to perform a microbiological analysis of the food items served during the meeting as there were no leftovers available when food items at the time the outbreak investigation was initiated.

\section{Environmental investigation}

The Food Safety Authority found several irregularities during their inspection of the hotel's kitchen. In particular, they observed incorrect washing routines and storage of dishes, there was inadequate management and control of the cooling of heat-treated foods, only one operative hand-washing point in the whole kitchen, and insufficient cleaning or disinfection of work surfaces, crockery and cutlery. Following the outbreak, the Food Safety Authority gave specific orders and rules to the hotel regarding correct methods of cleaning to be carried out by the kitchen staff. None of the food handlers or kitchen staff reported having been sick in the days or weeks before to the outbreak.

\section{Discussion and conclusion}

This outbreak did not have serious public health consequences: the number of people affected was low (attack rate: $14 \%$ ), very few people consulted their doctor, nobody was hospitalised and there was no media attention. We carried out a complete outbreak investigation in order to prevent possible future outbreaks, since the hotel where the outbreak happened is a very popular location for national and international meetings and events. As this hotel also provides accommodation for tourists from other parts of Norway and other countries, any outbreak occurring in the hotel could potentially be of international concern. Although these types of outbreaks are preventable, they still happen in places where they would not be expected, due to supposedly high quality of service, such as in this hotel.

The results of the microbiological analysis confirmed that the outbreak was caused by norovirus. Although we only had three positive stool samples, there were no indications that other pathogens were involved. Furthermore, most of the cases reported becoming ill between 24 and 72 hours after the meeting, which is in accordance with the incubation period for norovirus $[2,4]$. The clinical presentation of the disease also matched symptoms previously described for norovirus

\section{TABLE 2}

Characteristics of outbreak cases due to norovirus infection, one-day meeting, Oslo, Norway, 28 January 2011 ( $\mathrm{n}=56$ )

\begin{tabular}{|c|c|c|c|c|}
\hline Characteristic & Number of cases & Denominator & $\begin{array}{c}\text { Attack rate, as } \\
\text { percentage }\end{array}$ & Relative risk $(95 \% \mathrm{Cl})$ \\
\hline \multicolumn{5}{|l|}{ Sex } \\
\hline Male & 25 & 182 & 13.7 & - \\
\hline Female & 31 & 206 & 15.0 & $1.09(0.67-1.78)$ \\
\hline \multicolumn{5}{|l|}{ Age, in years } \\
\hline $40-59$ & 29 & 250 & 11.6 & $0.75(0.38-1.44)$ \\
\hline $60-74$ & 11 & 32 & $34 \cdot 4$ & $2.98(1.18-7.51)$ \\
\hline \multicolumn{5}{|l|}{ Contact with sick people ${ }^{a}$} \\
\hline During the four days before the meeting & 6 & 37 & 16.2 & $0.98(0.89-1.08)$ \\
\hline During the meeting & 4 & 34 & 11.8 & $1.02(0.94-1.10)$ \\
\hline
\end{tabular}

a Persons with diarrhoea, vomiting, fever and/or abdominal pain. 
infections [5-7]. Outbreaks of norovirus infection in hotels have been reported elsewhere, such as in $[8,9]$.

The specific source of this outbreak remains unclear. We know that a common source of infection was present during the meeting since the epicurve suggests a point-source transmission pattern, with a sudden increase of cases occurring just several hours after the meeting. It is not very likely that food served outside the hotel played a role in the outbreak since only six cases reported having eaten something not served during the meeting. Other people could have been infected more than 72 hours after the meeting, due to person-to-person transmission, which is very common in outbreaks due to norovirus $[9,10]$. However, in the questionnaire, we only asked about symptom onset during the 72-hour period following the meeting, as our main goal was to look for a possible common exposure during the meeting.

One of the main challenges we faced in this investigation related to the type of menu that was served. Since it was a set menu, almost everybody ate the same items, so for some of the food items very few people were unexposed. Therefore no further stratification and multivariable analysis was feasible. The results of the univariate analysis did not lead to strong conclusions. Those items that were closer to statistical significance were the sandwiches served for lunch and the wraps served during breakfast. The specific attack rates of the different food items were not very high, which suggests that there was not massive contamination of one specific food item, but that potentially several different items were contaminated. People who developed symptoms might have been sitting next to each other in the same area where contaminated food was served by the same waiter. However, we were not able to check this hypothesis.

We did not find any explanation as to why people aged 60 years and older were more likely to become ill. We found no specific food item that was more frequently eaten by meeting participants from this age group. It is possible that these participants had more underlying conditions, making them more prone to infection, as has been described previously in norovirus outbreaks $[11,12]$, but we did not collect information on this.

We consider that the outbreak was probably caused by contaminated food either from food handlers, kitchen staff, waiters or meeting participants who were shedding the virus. One person who attended the meeting reported having had diarrhoea when they arrived at the hotel and might have contributed to the spread of the virus. We also have to take into account that some of the food items, such as the wraps, were produced

TABLE 3

Exposure to foods ${ }^{\mathrm{a}}$, outbreak cases due to norovirus infection, one-day meeting, Oslo, Norway, 28 January 2011 (n=56)

\begin{tabular}{|c|c|c|c|c|c|c|c|c|c|}
\hline \multirow[b]{2}{*}{$\begin{array}{l}\text { Food items } s^{a} \text { at } \\
\text { each meal }\end{array}$} & \multicolumn{3}{|c|}{ Food eaten } & \multicolumn{3}{|c|}{ Food not eaten } & \multirow[b]{2}{*}{$\begin{array}{l}\text { Relative risk } \\
(95 \% \mathrm{Cl})\end{array}$} & \multirow[b]{2}{*}{$\begin{array}{c}P \\
\text { value }\end{array}$} & \multirow[b]{2}{*}{$\begin{array}{l}\text { Percentage } \\
\text { of cases } \\
\text { exposed }^{b}\end{array}$} \\
\hline & $\begin{array}{l}\text { Number } \\
\text { of cases }\end{array}$ & $\begin{array}{c}\text { Total } \\
\text { number of } \\
\text { participants }\end{array}$ & $\begin{array}{c}\text { Attack } \\
\text { rate, as } \\
\text { percentage }\end{array}$ & $\begin{array}{l}\text { Number } \\
\text { of } \\
\text { cases }\end{array}$ & $\begin{array}{c}\text { Total } \\
\text { number of } \\
\text { participants }\end{array}$ & $\begin{array}{c}\text { Attack } \\
\text { rate, as } \\
\text { percentage }\end{array}$ & & & \\
\hline \multicolumn{10}{|l|}{ Breakfast } \\
\hline $\begin{array}{l}\text { Wraps with } \\
\text { cheese, ham } \\
\text { and salad }\end{array}$ & 29 & 159 & 18.2 & 27 & 229 & 11.8 & $1.5(0.9-2.5)$ & 0.075 & 51.8 \\
\hline \multicolumn{10}{|l|}{ Lunch } \\
\hline $\begin{array}{l}\text { Sandwiches } \\
\text { with cheese } \\
\text { and salad }\end{array}$ & 39 & 204 & 19.1 & 4 & 47 & 8.5 & $2.3(0.8-6.0)$ & 0.082 & 69.6 \\
\hline $\begin{array}{l}\text { Borek with } \\
\text { spinach and } \\
\text { cheese }\end{array}$ & 24 & 144 & 16.7 & 6 & 59 & 10.2 & $1.6(0.7-3.8)$ & 0.236 & 42.9 \\
\hline Pastries & 11 & 79 & 13.9 & 9 & 84 & 10.7 & $1.3(0.6-3.0)$ & 0.532 & 19.6 \\
\hline \multicolumn{10}{|l|}{ Dinner } \\
\hline $\begin{array}{l}\text { Starter: } \\
\text { pickled cod }\end{array}$ & 54 & 349 & 15.5 & 1 & 10 & 10.0 & $1.5(0.2-10.1)$ & 0.636 & 96.4 \\
\hline $\begin{array}{l}\text { Main dish: } \\
\text { reindeer } \\
\text { médaillons }\end{array}$ & 54 & 348 & 15.5 & 0 & 10 & 0.0 & - & - & 96.4 \\
\hline $\begin{array}{l}\text { Dessert: } \\
\text { chocolate- } \\
\text { flavoured } \\
\text { liquorice }\end{array}$ & 53 & 339 & 15.6 & 1 & 18 & 5.6 & $2.8(0.4-19.2)$ & 0.245 & 94.6 \\
\hline
\end{tabular}

a Only food items with a relative risk greater than one are shown.

${ }^{b}$ Calculations were carried out using as the numerator the number of cases who answered that they were sure that they had eaten a specific food item and the total number of cases $(n=56)$ as the denominator. 
outside of the hotel, so the contamination could have happened before or during delivery to the hotel.

The irregularities that the Food Safety Authority's inspection found in the kitchen may have enabled the spread of the virus. Handling of ready-to-eat foods by infected food handlers is commonly identified as a contributing factor in outbreaks caused by norovirus [13-15]. However, the role of kitchen employees or food handlers in the outbreak reported here remains unclear since none of those in the hotel reported any symptoms to the Food Safety Authority and no information was available regarding the health status of the food handlers who produced some of the food items outside the hotel. The importance of identifying asymptomatic food handlers shedding the virus is also well described in the literature: such people can also be a contributing factor in norovirus outbreaks $[16,17]$. We do not know if asymptomatic food handlers were involved in the spread of the virus in this outbreak as the employees were not asked to provide stool samples.

We would like to emphasise the importance of performing a complete outbreak investigation, looking at all epidemiological, environmental and microbiological components, when norovirus outbreaks occur. All three are equally important and complementary. In this outbreak, the epidemiological investigation of the food items served was inconclusive, but the microbiological analysis revealed the identity of the pathogen and the environmental investigation revealed several irregularities in the kitchen.

Specific recommendations, orders and rules were given by the Food Safety Authority for the correct cleaning and management of the kitchen. The Food Safety Authority followed up with the hotel to ensure implementation of the recommendations and to verify that all the irregularities had been addressed within the deadline proposed. As a consequence of this outbreak investigation, the hotel is planning to change their internal, routine protocols, for example, samples of food items served at every meal in an event will be stored, in case a similar situation happens again and analysis of the food is needed.

Food handlers and other personnel who present with gastrointestinal symptoms should avoid involvement with the preparation of food while they are symptomatic in order to prevent spread of the pathogen, and they should also adhere to appropiate hygiene and hand-washing routines.

\section{Acknowledgements}

We would like to acknowledge the following colleagues for their contribution to this outbreak investigation: Katrine Borgen (Norwegian Institute of Public Health and EPIET supervisor, Oslo, Norway), Emily MacDonald (Norwegian Institute of Public Health, Oslo, Norway) and Alicia Barrasa (EPIET coordinator, Instituto Carlos III Madrid, Spain).
References

1. National Center for Immunization and Respiratory Diseases, Centers for Disease Control and Prevention (CDC). Norovirus: technical fact sheet. Atlanta: CDC. [Accessed 23 May 2011]. http://www.cdc.gov/ncidod/dvrd/revb/gastro/norovirusfactsheet.htm

2. World Health Organization (WHO). Diarrhoeal diseases (updated February 2009). Available from: http://www.who.int/ vaccine_research/diseases/diarrhoeal/en/index.html

3. Vold L, Heier BT, Comelli H, Nygård K, Kapperud G. Årsreport: Matbårne infeksjoner og utbrudd i 2010 [Annual report: food-borne diseases and outbreaks in 2010]. Oslo: Nasjonalt folkehelseinstitutt; 2011. Norwegian. Available from: http:// www.fhi.no/dokumenter/cd8fa1273d.pdf

4. Nasjonalt folkehelseinstitutt. Norovirusenteritt. Smittevernboka [Gastroenteritis caused by norovirus. Manual for communicable diseases control]. Oslo: Nasjonalt folkehelseinstitutt: 2010. [Accessed 25 May 2011]. Available from: http://www.fhi.no/eway/default.aspx?pid=233\&trg=Mai nLeft_6039\&MainArea_5661=6039:0:15,5078:1:0:0:::0:0\&Mai nLeft_6039=6041:82829::1:6043:88:::0:0

5. Nygård K, Vold L, Halvorsen E, Bringeland E, Røttingen JA, Aavitsland P. Waterborne outbreak of gastroenteritis in a religious summer camp in Norway. 2002. Epidemiol Infect. 2004;132(2):223-9.

6. Division of Viral Diseases, National Center for Immunization and Respiratory Diseases, Centers for Disease Control and Prevention. Updated norovirus outbreak management and disease prevention guidelines. MMWR Recomm Rep. 2011;60(RR-3):1-18.

7. Mattner F, Sohr D, Gastmeier P, Vennema H, Koomans M. Risk groups for clinical complications of norovirus infections: an outbreak investigation. Clin Microbiol Infect. 2006;12:69-74.

8. Domenech-Sanchez A. Gastroenteritis outbreak caused by norovirus associated with the children's club of a hotel located in Majorca, Spain. Clin Microbiol Infect. 2011;17:949-51.

9. Michel A, Fitzgerald R, Whyte D, Fitzgerald A, Beggan E, O'Connell $\mathrm{N}$, et al. Norovirus outbreak associated with a hotel in the west of Ireland, 2006. Euro Surveill. 2007;12(7):pii=725. Available from: http://www.eurosurveillance.org/ViewArticle. aspx?Articleld $=725$

10. Mesquita JR, Nascimento MS. A foodborne outbreak of norovirus gastroenteritis associated with a Christmas dinner in Porto, Portugal, December 2008. Euro Surveill. 2009;14(41):pii=19355. Available from: http://www. eurosurveillance.org/ViewArticle.aspx?Articleld=19355

11. Friesema IH, Vennema H, Heijne JC, de Jager CM, Teunis PF, van der Linde $\mathrm{R}$, et al. Differences in clinical presentation between norovirus genotypes in nursing homes. J Clin Virol. 2009;46(4):341-4.

12. Haustein T, Harris JP, Pebody R, Lopman BA. Hospital admissions due to norovirus in adult and elderly patients in England. Clin Infect Dis. 2009;49(12):1890-2.

13. Zomer TP, De Jong B, Kühlmann-Berenzon S, Nyrén O, Svenungsson B, Hedlund $\mathrm{KO}$, et al. A foodborne norovirus outbreak at a manufacturing company. Epidemiol infect. 2010;138(4):501-6.

14. Schmid D, Stüger HP, Lederer I, Pichler AM, Kainz-Arnfelser G, Schreier E, et al. A foodborne norovirus outbreak due to manually prepared salad, Austria 2006. Infection. 2007;35(4):232-9.

15. Baert L, Uyttendaele M, Stals A, Van Coillie E, Dierick K, Debevere J, Botteldoorn N. Reported foodborne outbreaks due to noroviruses in Belgium: the link between food and patient investigations in an international context. Epidemiol Infect. 2009;137(3):316-25.

16. Barrabeig I, Rovira A, Buesa J, Bartolomé R, Pintó R, Prellezo $\mathrm{H}$, et al. Foodborne norovirus outbreak: the role of an asymptomatic food handler. BMC Infect Dis. 201010:269.

17. Ozawa K, Oka T, Takeda N, Hansman G. Norovirus infections in symptomatic and asymptomatic food handlers in Japan. J Clin Microbiol. 2007;45(12):3996-4005. 